\title{
Adjustment of A Simplified Satellite-Based Algorithm for Gross Primary Production Estimation Over Korea
}

\author{
Kyoung-Jin $\mathrm{Pi}^{\star}$, Kyung-Soo Han ${ }^{\star \dagger}$, In-Hwan Kim, Tae-yoon Lee* and Jae-Il Jo* \\ * Department of Spatial Information Engineering, Pukyong National University \\ ** Department of Environmental Engineering, Pukyong National University
}

\begin{abstract}
Monitoring the global Gross Primary Pproduction (GPP) is relevant to understanding the global carbon cycle and evaluating the effects of interannual climate variation on food and fiber production. GPP, the flux of carbon into ecosystems via photosynthetic assimilation, is an important variable in the global carbon cycle and a key process in land surface?atmosphere interactions. The Moderate-resolution Imaging Spectroradiometer (MODIS) is one of the primary global monitoring sensors. MODIS GPP has some of the problems that have been proven in several studies. Therefore this study was to solve the regional mismatch that occurs when using the MODIS GPP global product over Korea. To solve this problem, we estimated each of the GPP component variables separately to improve the GPP estimates. We compared our GPP estimates with validation GPP data to assess their accuracy. For all sites, the correlation was close with high significance $\left(R^{2}=0.8164\right.$, RMSE $=0.6126 \mathrm{~g} \cdot \mathrm{C} \cdot \mathrm{m}^{-2} \cdot \mathrm{d}^{-1}$, bias $\left.=-0.0271 \mathrm{~g} \cdot \mathrm{C} \cdot \mathrm{m}^{-2} \cdot \mathrm{d}^{-1}\right)$. We also compared our results to those of other models. The component variables tended to be either over- or under-estimated when compared to those in other studies over the Korean peninsula, although the estimated GPP was better. The results of this study will likely improve carbon cycle modeling by capturing finer patterns with an integrated method of remote sensing.
\end{abstract}

Key Words : GPP, MODIS, Korea peninsula, Vegetation Index

\section{Introduction}

Vegetation primary production is vital to human society because it provides essential materials and environments suitable for human habitation (Zhao et al., 2006). Primary production has received increasing attention in recent years and is directly related to the global carbon cycle. The atmospheric concentration of
$\mathrm{CO}_{2}$ has increased by $31 \%$ since 1750 (IPCC, 2001) due to human activities. This increase can alter the energy balance of the land surface and change the climate (Knutson et al., 1999; Scott et al., 2000). The terrestrial biosphere can sequester significant amounts of atmospheric $\mathrm{CO}_{2}$ (Wofsy et al., 1993), a process that is largely influenced by the increased atmospheric $\mathrm{CO}_{2}$ and the changing climate (Nemani et al., 2002, 2003;

Received June 12, 2013; Accepted June 21, 2013.

Corresponding Author: Kyung-Soo Han(kyung-soo.han@pknu.ac.kr)

This is an Open-Access article distributed under the terms of the Creative Commons Attribution Non-Commercial License (http:/creativecommons.org/ licenses/ by-nc/3.0) which permits unrestricted non-commercial use, distribution, and reproduction in any medium, provided the original work is properly cited 
Schimel et al., 2000). The magnitude and cause of carbon uptake are still uncertain (Barford et al., 2001) and knowledge of the carbon cycle on regional and global scales is required to understand spatial and temporal monitoring of earth surface processes (Running et al., 1999). Monitoring the global Gross Primary Production (GPP) is relevant to understanding the global carbon cycle and evaluating the effects of interannual climate variation on food and fiber production (Running et al., 1999). GPP, the flux of carbon into ecosystems via photosynthetic assimilation, is an important variable in the global carbon cycle and a key process in land surface-atmosphere interactions (Coops et al., 2009; Jung et al., 2008). The continuous monitoring of GPP in general, and the highly accurate spatial and temporal variations on a regional scale in particular, can provide reliable data for carbon-related climate change studies and useful information for ecosystem management (Wang et al., 2010). One of the most widely used concepts for modeling GPP is the Light-Use Efficiency (LUE) approach of Monteith $(1972,1977)$. This expresses GPP $\left(\mathrm{g} \cdot \mathrm{C} \cdot \mathrm{m}^{-2} \cdot \mathrm{d}^{-1}\right)$ as the product of the absorbed Photosynthetically Active Radiation (PAR) $\left(\mathrm{MJ} \cdot \mathrm{m}^{-2} \cdot \mathrm{d}^{-1}\right)$, which is defined as absorbed solar radiation with a wavelength of 400-700 nm, and the efficiency with which the absorbed PAR can be converted into biomass:

$$
G P P=F P A R \times P A R \times \varepsilon_{g}
$$

where FPAR (photosynthetically active radiation absorbed by vegetation) represents the fraction of PAR absorbed by the canopy and $\varepsilon_{g}\left(\mathrm{~g} \cdot \mathrm{C} \cdot \mathrm{MJ}^{-1}\right)$ is the photosynthetic efficiency term. The LUE concept is based on the functional convergence theory (Field, 1991) hypothesizing that plants scale the canopy leaf area and light harvesting by the availability of resources as a result of evolutionary processes to optimize their carbon fixation (Goetz et al., 1999).

The Moderate-resolution Imaging Spectroradiometer (MODIS) is one of the primary global monitoring sensors. The MODIS GPP algorithm's key components are the Data Assimilation Office (DAO) climate data, the MODIS FPAR, and the parameterization of the LUE lookup table (Running et al., 2000). This study revealed a variety of differences between those components implemented in 2001 and ground-based measurements. Because of the comprehensive archiving of MODIS data, reprocessing of data for specific algorithms will be possible at any time during the expected five-year lifetime of the sensor. It is thus worth considering possible improvements.

There will always be limitations for DAO data in the degree to which the general circulation model-based estimates agree with ground measurements at particular sites because of the coarse scale of the DAO model outputs (Turner et al., 2003). The differences observed in this analysis are related to this mismatch in scale as well as possible limitations of the DAO product. While the MODIS FPAR product captures the high midgrowing season values, problems appear to exist outside the growing season. Their effect on the MODIS GPP product is limited because the PAR and minimum temperature scalar are usually low in any case. The MODIS FPAR has a strong spring green-up signal and appears to achieve its summer maximum somewhat earlier than indicated by ground measurements. This causes a corresponding overestimation of GPP early in the growing season. The MODIS Leaf Area Index (LAI) product does show the autumn leaf drop (Cohen et al., 2003), so the FPAR algorithm could be modified to capture this effect. The MODIS $\varepsilon_{g}$ parameterization is perhaps the most amenable to modification of all the algorithm's components because it relies on a simple lookup table. The threshold and maximum for the Vapor Pressure Deficit (VPD) scalar have already been modified once. The original biome-specific $\varepsilon_{g}$ maxima and scalar parameterizations were based on model outputs rather than on observations of $\varepsilon_{g}$, and there is significant potential for improvement now that an extensive global network of eddy covariance flux 
towers is in place (Running et al., 1999).

Turner et al.(2003) evaluated MODIS GPP products with GPP values derived from the measured net ecosystem exchange in flux towers, which were part of FLUXNET, a network of micrometeorological tower sites that used eddy covariance methods to measure the exchanges of $\mathrm{CO}_{2}$, water vapor, and energy between terrestrial ecosystems and the atmosphere. They analyzed the 2001 MODIS data set at two sites and showed that, relative to tower-based estimates, MODIS overestimated GPP by $35 \%$ in boreal forest areas, whereas estimates were within the accuracy of the tower results for temperate zone hardwood forest areas. Gebremichael and Barros (2006) studied the quantitative estimation of the uncertainty associated with MODIS GPP end-products that depend on several MODIS-derived vegetation indices. The MODIS GPP products were compared against simulations made with a process-based biochemical-hydrology model driven by flux tower meteorological observations. They examined the error contribution from the DAO meteorological data used in standard MODIS GPP products. Their results showed that the bias between the GPP estimates using DAO and tower meteorology was $77 \%$ of the mean of the tower-based GPP.

The object of this study was to solve the regional mismatch that occurs when using the GPP global product over Korea. We also estimated the GPP production from remotely sensed inputs and developed remote-sensing-based models of the terrestrial carbon cycle. To achieve this, we used a different approach to determine each component variable in the GPP estimate. First, we first used atmospheric corrections, reflectance normalizations, and Normalized Difference Vegetation Index (NDVI) corrections to calculate the FPAR. Second, we estimated the PAR using the physical model of Yeom (2010). Without relying on ground observations, we estimated $\varepsilon_{g}$ based on important environmental parameters such as soil moisture.

\section{DATA}

\section{1) Data set}

The study area was a section of Northeast Asia bounded by $32.50-40.0^{\circ} \mathrm{N}$ and $124.48-130.0^{\circ} \mathrm{E}$. The GPP was estimated over the study period of January 1 to December 31, 2006. This study used MODIS products (FPAR/LAI and GPP), VEGETATION sensor data, MTSAT-1R data, and meteorological data to estimate the GPP. We used the 8-day LAI and FPAR data sets from the Land Processes Distributed Active Archive Center web site at https://lpdaac.usgs.gov/. The MOD15 LAI and FPAR are $1 \mathrm{~km}$ (at launch) products provided on a daily and eight-day basis (Myneni et al., 2003). The MODIS LAI/FPAR algorithm consists of a main procedure that exploits the spectral information content of MODIS surface reflectance in up to seven spectral bands based on a three-dimensional formulation of the LAI/FPAR inverse problem. Should the main algorithm fail, a backup algorithm is triggered to estimate the LAI and FPAR using vegetation indices (Myneni et al., 2003). The MOD17A2 algorithm provides the first operational, near-real-time calculation of global GPP products from the EOS MODIS sensor. It also produces the eight-day composite GPP, net photosynthesis (PsnNet), and corresponding Quality Control (QC). While GPP is calculated on a daily basis, eight-day GPP summaries are made publicly available.

The SPOT/VEGETATION (VGT) sensor developed by the Centre National d'Etudes Spatiales provides daily monitoring of terrestrial characteristics such as surface albedo, reflectance, and vegetation indices, which are obtained on a global scale from remotely sensed data. The VGT sensor provides daily global images with a $1-\mathrm{km}$ spatial resolution. We acquired the VGT S10 product for the period JanuaryDecember 2006. Vegetation indices such as NDVI, Fraction of Vegetation Cover (FVC), and Normalized Difference Water Index (NDWI) were calculated for 
Table 1. Locations of the 76 meteorological stations

\begin{tabular}{|c|c|c|c|c|c|c|c|}
\hline Station No. & Station name & Latitude (N) & Longitude (E) & Station No. & Station name & Latitude (N) & Longitude(E) \\
\hline 90 & Sokcho & 38.2481 & 128.5670 & 185 & Gosan & 33.2833 & 126.1667 \\
\hline 95 & Cheorwon & 38.1451 & 127.3063 & 189 & Seogwipo & 33.2428 & 126.5674 \\
\hline 98 & Dongducheon & 37.8991 & 127.0628 & 192 & Jinju & 35.2054 & 128.1213 \\
\hline 99 & Munsan & 37.8844 & 126.7625 & 201 & Ganghwa & 37.7046 & 126.4486 \\
\hline 100 & Deagwallyeong & 37.6841 & 128.7610 & 202 & Yangpyeong & 37.4858 & 127.4966 \\
\hline 101 & Chuncheon & 37.8999 & 127.7379 & 203 & Icheon & 37.2611 & 127.4863 \\
\hline 102 & Baengnyeong & 37.9661 & 124.6305 & 211 & Inje & 38.0573 & 128.1692 \\
\hline 105 & Gangneung & 37.7486 & 128.8933 & 212 & Hongcheon & 37.6808 & 127.8826 \\
\hline 106 & Donghae & 37.5043 & 129.1266 & 216 & Taebaek & 37.1675 & 128.9915 \\
\hline 108 & Seoul & 37.5714 & 126.9658 & 221 & Jecheon & 37.1564 & 128.1965 \\
\hline 112 & Incheon & 37.4747 & 126.6266 & 226 & Boeun & 36.4847 & 127.7363 \\
\hline 114 & Wonju & 37.3340 & 127.9504 & 232 & Cheonan & 36.7767 & 127.1213 \\
\hline 115 & Ulleung & 37.4800 & 130.9000 & 235 & Boryeong & 36.3243 & 126.5594 \\
\hline 119 & Suwon & 37.2695 & 126.9875 & 236 & Buyeo & 36.2694 & 126.9229 \\
\hline 121 & Yeongwol & 37.1784 & 128.4597 & 238 & Geumsan & 36.1027 & 127.4839 \\
\hline 127 & Chungju & 36.9672 & 127.9522 & 243 & Buan & 35.7265 & 126.7186 \\
\hline 129 & Seosan & 36.7737 & 126.4959 & 244 & Imsil & 35.6092 & 127.2877 \\
\hline 130 & Uljin & 36.9889 & 129.4153 & 245 & Jeongeup & 35.5601 & 126.8682 \\
\hline 131 & Cheongju & 36.6363 & 127.4428 & 247 & Namwon & 35.4023 & 127.3351 \\
\hline 133 & Daejeon & 36.3690 & 127.3742 & 248 & Jangsu & 35.6539 & 127.5224 \\
\hline 135 & Chupungueong & 36.2170 & 127.9967 & 256 & Suncheon & 35.0719 & 127.2412 \\
\hline 136 & Andong & 36.5701 & 128.7095 & 260 & Jangheung & 34.6856 & 126.9216 \\
\hline 137 & Sangju & 36.4000 & 128.1500 & 261 & Haenam & 34.5504 & 126.5711 \\
\hline 138 & Pohang & 36.0297 & 129.3820 & 262 & Goheung & 34.6151 & 127.2778 \\
\hline 140 & Gunsan & 36.0022 & 126.7633 & 265 & Seongsanpo & 33.3836 & 126.8824 \\
\hline 143 & Deagu & 35.8822 & 128.6212 & 271 & Bonghwa & 36.9407 & 128.9168 \\
\hline 146 & Jeongu & 35.8185 & 127.1571 & 272 & Yeongju & 36.8689 & 128.5191 \\
\hline 152 & Ulsan & 35.5571 & 129.3225 & 273 & Mungyeong & 36.6243 & 128.1510 \\
\hline 155 & Masan & 35.1671 & 128.5751 & 277 & Yeongdeok & 36.5304 & 129.4117 \\
\hline 156 & Gwangju & 35.1698 & 126.8936 & 278 & Uiseong & 36.3531 & 128.6908 \\
\hline 159 & Busan & 35.1016 & 129.0343 & 279 & Gumi & 36.1276 & 128.3228 \\
\hline 162 & Tongyeong & 34.8423 & 128.4378 & 281 & Yeongcheon & 35.9744 & 128.9537 \\
\hline 165 & Mokpo & 34.8138 & 126.3832 & 284 & Geochang & 35.6682 & 127.9132 \\
\hline 168 & Yeosu & 34.7362 & 127.7428 & 285 & Hapcheon & 35.5620 & 128.1720 \\
\hline 169 & Heuksando & 34.6833 & 125.4500 & 288 & Miryang & 35.4885 & 128.7464 \\
\hline 170 & Wando & 34.3927 & 126.7039 & 289 & Sancheong & 35.4099 & 127.8813 \\
\hline 175 & Jindo & 34.4720 & 126.3236 & 294 & Geoje & 34.8851 & 128.6067 \\
\hline 184 & Jeju & 33.5109 & 126.5317 & 295 & Namhae & 34.8135 & 127.9286 \\
\hline
\end{tabular}

all the 10-day composite images.

MTSAT-1R, operated by the Japanese Meteorological Agency and controlled by the Civil Aviation Bureau of the Ministry of Land, Infrastructure, and Transport, was successfully launched on February 26, 2005. This study used hourly data and considered all the bands as potential input data. All of the MTSAT-1R data were obtained from the National Institute of Meteorological Research and were sufficient to produce values for normalized reflectance, surface albedo, and solar 


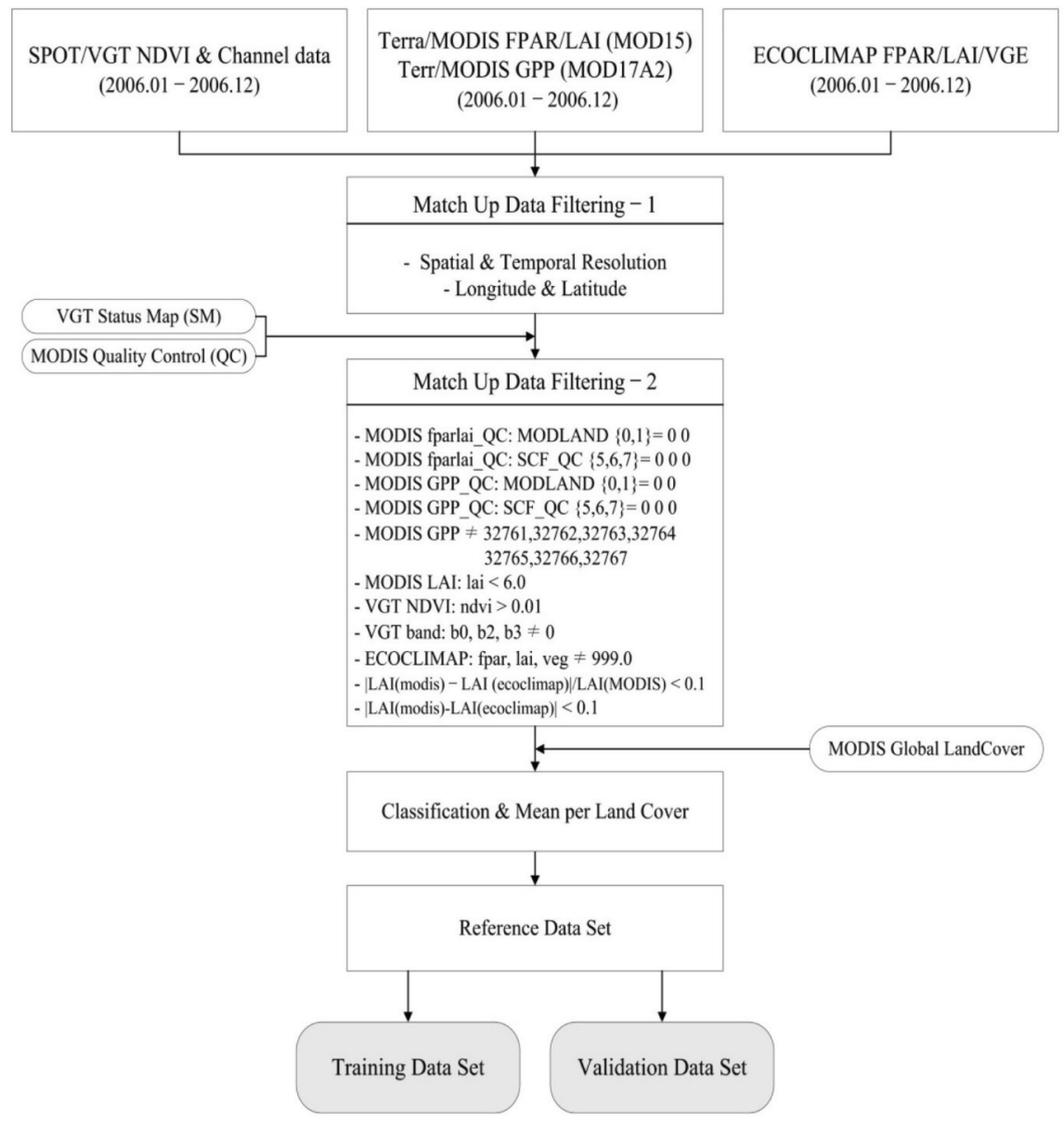

Fig. 1. Flowchart of reference data filtering process using MODIS QC and VGT SM.

surface insolation.

Ground observation takes place using automated equipment at 76 manned stations located as shown in Table 1. The ground-based measurement data were acquired from the Korea Meteorological Administration in 2006. The 16 elements including pressure, temperature, humidity, precipitation, cloud coverage, wind, and solar radiation are measured every three hours. The dense surface observation data collected from automatic weather stations also play an important role in the preparation of the initial conditions for the numerical prediction models. We used two kinds of meteorological data: temperature and solar radiation. Temperature data were used to estimate $T_{a}$ with MODIS Land-Surface Temperature (LST) data, and solar radiation data was used to estimate PAR.

\section{2) Reference data set}

Before starting this study, reference data were established to improve the accuracy of the results. Fig. 1 shows a flowchart of the reference data filtering process. First, geometric correction was used to match the three types (SPOT/VGT, Terra/MODIS, and ECOCLIMAP) of data over the study area with a spatial resolution of $1 \mathrm{~km}$. The nearest-neighbor method was used to correct geometric distortion. The temporal resolution was also corrected to the MODIS 8-day baseline because the VGT S10 and ECOCLIMAP data were in 10-day composite images. The SPOT/ VGT dataset included one status map for radiometric 
quality, cloud masks, and snow masks. The MODIS data set included the QC, the definition of which was optimized during data reprocessing. The QC field in MOD17A2 was inherited from MOD15A2, and each pixel's QC value was based on the sensor and cloud conditions. As previously stated, we used quality data, i.e., Status Map (SM) and QC, to improve the accuracy of the results. Eleven conditions were used to select the reference collocation pixels. The conditions for the reference pixels were as follows:

\section{CONDITIONS}

- MODIS FPAR/LAI_QC: MODLAND $\{0,1\}=00$

- MODIS FPARLAI_QC: SCF_QC $\{5,6,7\}=000$

- MODIS GPP_QC:MODLAND $\{0,1\}=00$

- MODIS GPP_QC: SCF_QC $\{5,6,7\}=000$

- MODIS GPP $\neq 32761,32762,32763,32764,32765,32766$, 32767

- MODIS LAI: lai $<6.0$

- VGT NDVI: $n d v i>0.01$

- VGT band: $b 0, b 2, b 3 \neq 0$

- ECOCLIMAP: fpar, lai, veg $\neq 999.0$

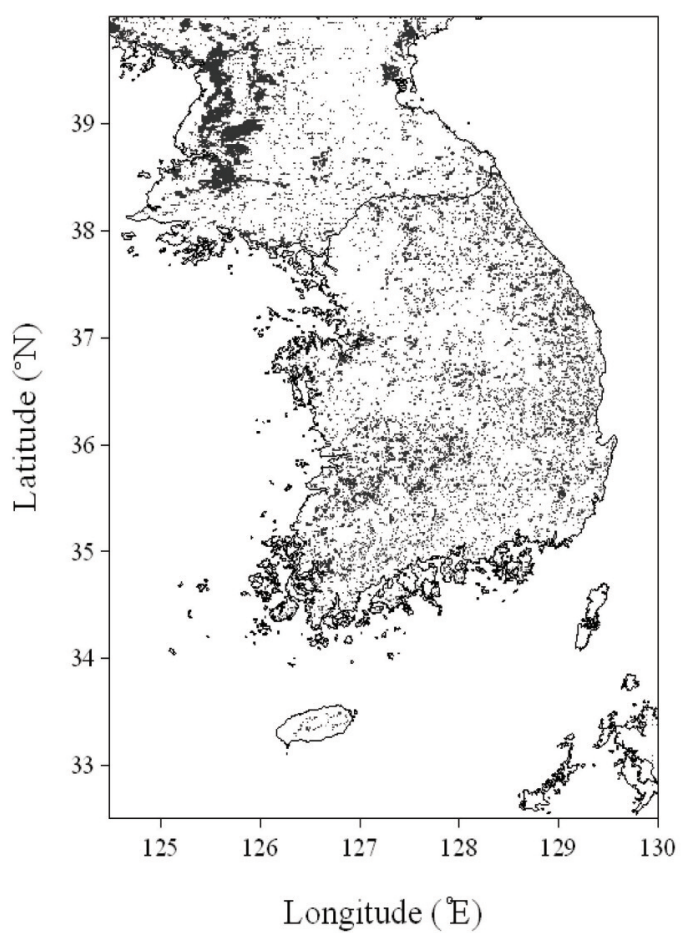

Fig. 2. Filtering results. Black point are pixels selected on Julian day 49,2006 .
Table 2. Number of samples quality control of best flagged pixel of MODIS QC map

\begin{tabular}{|c|c|c|c|}
\hline $\begin{array}{c}\text { Data } \\
\text { (8-day) }\end{array}$ & $\begin{array}{l}\text { Cropland } \\
\text { (No. of pixels) }\end{array}$ & $\begin{array}{c}\text { Forest } \\
\text { (No. of pixels) }\end{array}$ & $\begin{array}{c}\text { Total } \\
\text { (No. of pixels) }\end{array}$ \\
\hline 2006001 & $12,726(49.5 \%)$ & $12,976(50.5 \%)$ & 25,702 \\
\hline 2006009 & $12,276(48.8 \%)$ & $12,860(51.2 \%)$ & 25,136 \\
\hline 2006017 & $11,430(46.2 \%)$ & $13,308(53.8 \%)$ & 24,738 \\
\hline 2006025 & $12,541(48.6 \%)$ & $13,273(51.4 \%)$ & 25,814 \\
\hline 2006033 & $12,873(49.6 \%)$ & $13,059(50.4 \%)$ & 25,932 \\
\hline 2006041 & $13,909(51.2 \%)$ & $13,250(48.8 \%)$ & 27,159 \\
\hline 2006049 & $13,964(50.8 \%)$ & $13,534(49.2 \%)$ & 27,498 \\
\hline 2006057 & $13,959(51.1 \%)$ & $13,369(48.9 \%)$ & 27,328 \\
\hline 2006065 & $13,952(51.1 \%)$ & $13,336(48.9 \%)$ & 27,288 \\
\hline 2006073 & $13,959(50.8 \%)$ & $13,533(49.2 \%)$ & 27,492 \\
\hline 2006081 & $13,966(50.8 \%)$ & $13,542(49.2 \%)$ & 27,508 \\
\hline 2006089 & $13,964(50.8 \%)$ & $13,544(49.2 \%)$ & 27,508 \\
\hline 2006097 & $13,964(50.8 \%)$ & $13,527(49.2 \%)$ & 27,491 \\
\hline 2006105 & $13,960(50.9 \%)$ & $13,493(49.1 \%)$ & 27,453 \\
\hline 2006113 & $13,965(50.8 \%)$ & $13,534(49.2 \%)$ & 27,499 \\
\hline 2006121 & $13,963(51.4 \%)$ & $13,186(48.6 \%)$ & 27,149 \\
\hline 2006129 & $13,932(70.1 \%)$ & $5,947(29.9 \%)$ & 19,879 \\
\hline 2006137 & $13,927(78.8 \%)$ & $3,752(21.2 \%)$ & 17,679 \\
\hline 2006145 & $13,963(80.9 \%)$ & $3,286(19.1 \%)$ & 17,249 \\
\hline 2006153 & $13,912(86.9 \%)$ & $2,091(13.1 \%)$ & 16,003 \\
\hline 2006161 & $13,918(87.2 \%)$ & $2,052(12.8 \%)$ & 15,970 \\
\hline 2006169 & $13,942(77.6 \%)$ & $4,030(22.4 \%)$ & 17,972 \\
\hline 2006177 & $13,313(92.5 \%)$ & $1,084(7.5 \%)$ & 14,397 \\
\hline 2006185 & $10,696(98.4 \%)$ & $175(1.6 \%)$ & 10,871 \\
\hline 2006193 & $6,830(94.5 \%)$ & $399(5.5 \%)$ & 7,229 \\
\hline 2006201 & $10,699(89.4 \%)$ & $1,268(10.6 \%)$ & 11,967 \\
\hline 2006209 & $11,884(82.2 \%)$ & $258(17.8 \%)$ & 14,465 \\
\hline 2006217 & $12,874(77.7 \%)$ & $3,703(22.3 \%)$ & 16,577 \\
\hline 2006225 & $12,976(78.0 \%)$ & $3,454(21.0 \%)$ & 16,430 \\
\hline 2006233 & $12,163(89.3 \%)$ & $1,455(10.7 \%)$ & 13,618 \\
\hline 2006241 & $13,503(79.7 \%)$ & $3,444(20.3 \%)$ & 16,947 \\
\hline 2006249 & $13,785(82.4 \%)$ & $2,937(17.6 \%)$ & 16,722 \\
\hline 2006257 & $13,897(66.1 \%)$ & $7,114(33.9 \%)$ & 21,011 \\
\hline 2006265 & $13,909(81.6 \%)$ & $3,142(18.4 \%)$ & 17,051 \\
\hline 2006273 & $13,943(68.0 \%)$ & $6,567(32.0 \%)$ & 20,510 \\
\hline 2006281 & $13,940(58.1 \%)$ & $10,062(41.9 \%)$ & 24,002 \\
\hline 2006289 & $13,768(54.0 \%)$ & $11,718(45.0 \%)$ & 25,486 \\
\hline 2006297 & $13,961(52.2 \%)$ & $12,791(47.8 \%)$ & 26,752 \\
\hline 2006305 & $13,959(50.8 \%)$ & $13,501(49.2 \%)$ & 27,460 \\
\hline 2006313 & $13,963(50.8 \%)$ & $13,533(49.2 \%)$ & 27,496 \\
\hline 2006321 & $13,961(50.8 \%)$ & $13,534(49.2 \%)$ & 27,495 \\
\hline 2006329 & $13,951(51.5 \%)$ & $13,136(48.5 \%)$ & 27,087 \\
\hline 2006337 & $13,948(50.8 \%)$ & $13,499(49.2 \%)$ & 27,447 \\
\hline 2006345 & $13,493(52.5 \%)$ & $12,215(47.5 \%)$ & 25,708 \\
\hline 2006353 & $13,478(50.2 \%)$ & $13,356(49.8 \%)$ & 26,834 \\
\hline 2006361 & $13,451(50.1 \%)$ & $13,444(49.9 \%)$ & 26,895 \\
\hline
\end{tabular}


- ILAI(modis)-LAI(ecoclimap) / / LAI(MODIS) <0.1

- |LAI(modis)-LAI(ecoclimap) $\mid<0.1$

Fig. 2 shows the result obtained when reference pixels were selected to meet all the conditions. In this figure, black points represent the selected pixel by filtering on Julian day 49, 2006. The study area consisted of areas classified mainly as forest and cropland. Table 2 shows detailed information about the number of samples and QC of the pixel best flagged by the land cover classification. Because the QC information for each file was different, the number of selected pixels was also different. The final reference data were acquired such that the average was calculated for each type of land cover based on the result of the filtering process. Finally, the process above was used to select more reliable reference data. Reference data were used as the key data in estimating GPP, and selected from those with the best $\mathrm{QC}$ values.

\section{METHODOLOGY}

Fig. 3 explains the methodology used in this study. SPOT/VGT NDVI data were used to estimate the FPAR. To improve FPAR accuracy, we were applied to the model of Pi (2010). Pi presented that the FPAR is usually estimated by the LAI, but we estimated it directly using the FVC. We used an empirical method that is usually based on a linear or nonlinear function of vegetation indices. These results were compared with the validation reference FPAR data.

We estimated the PAR using the physical model of Yeom (2010). The first step included a calculation for the solar zenith angle and the varying distance between the earth and the sun. The next step was to parameterize atmospheric transmittance due to ozone, water vapor, aerosols, and Rayleigh scattering. Cloud mask information was used to classify pixels as clear or cloudy. In the case of cloudy sky, attenuation coefficients were used to estimate cloudy PAR. These

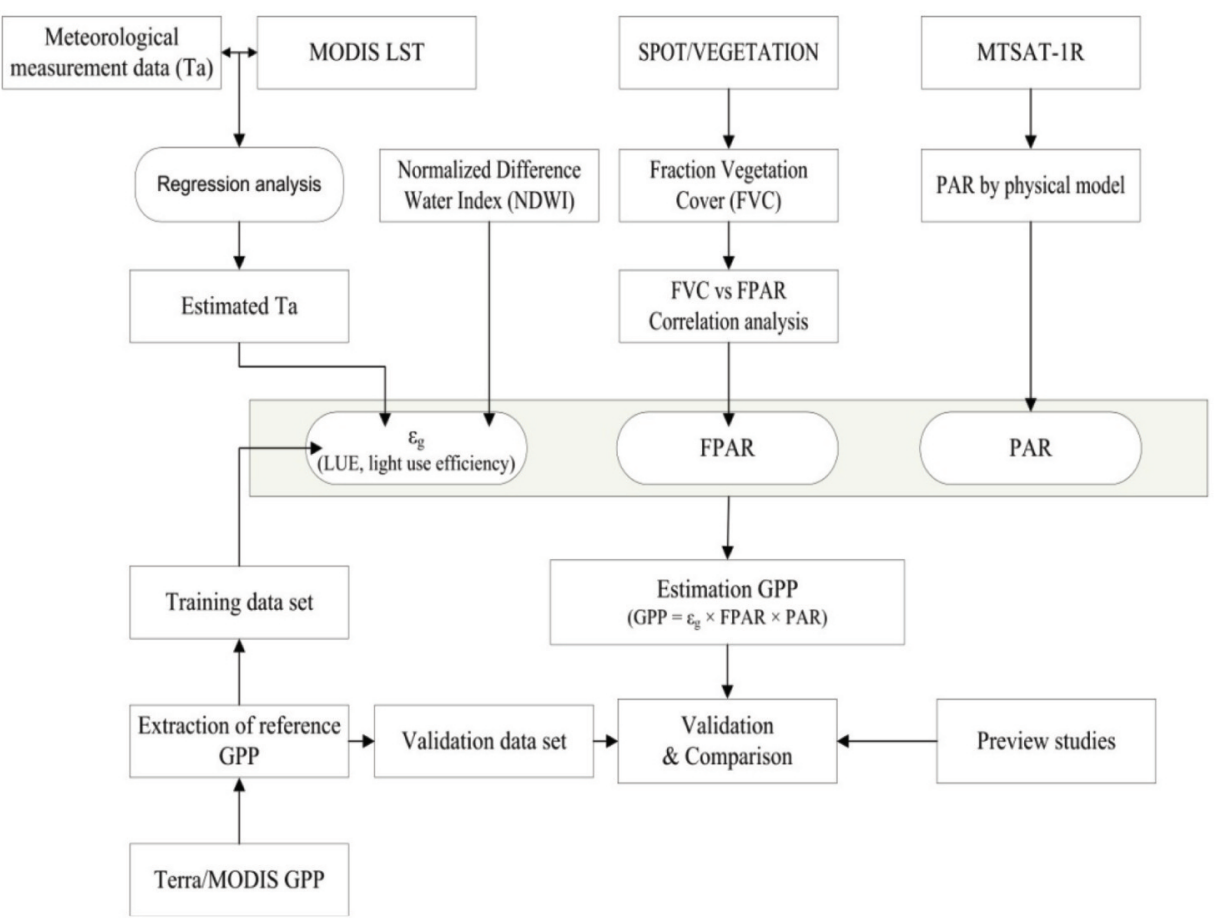

Fig. 3. Flowchart of gross primary production (GPP) modeling method. 
results were also compared with ground-based measured measurements.

We used the modified VPM model to estimate the GPP. The first step was to estimate satellite-based $T_{a}$ by regression analysis between the meteorological measurement data and MODIS LST. Next, the NDWI was estimated from SPOT/VGT spectral bands. We improved the input data to the VPM model and also improved the quality of $\varepsilon_{g}$. The data obtained this way were then applied to the VPM model. These results were compared with validation $\varepsilon_{g}$ reference data and also with $\varepsilon_{g}$ values calculated using other methods.

The final step was to estimate the GPP by applying the improved parameters. The three input variables (FPAR, PAR, and $\varepsilon_{g}$ ) were analyzed on correlation analysis scatter plots before they were used in the GPP. Finally, the estimated GPP was validated with the reference GPP data and compared with the MODIS GPP time series about a pixel that was selected at random. These results and those from other models were then compared to ascertain the suitability of the global product. Finally, we analyzed the spatial patterns of the GPP over the study area.

\section{RESULTS AND ANALYSIS}

\section{1) Estimation of FPAR and PAR}

The FPAR was estimated using an expression derived from Pi (2010). The following expressions were also derived:

$$
\mathrm{PAR}=\mathrm{FVC}_{\mathrm{adi}}+\mathrm{FVC}_{\mathrm{md}}{ }^{3} \cdot \mathrm{FVC}_{\mathrm{i}},
$$

where $F V C_{a d j}$ is the adjusted minimum FVC and $F V C_{m d}$ is the minimum $\mathrm{FVC}$ difference;

$$
\begin{gathered}
\mathrm{FVC}_{\text {adi }}=\mathrm{FVC}_{\text {min }} \cdot \omega \text { and } \\
\mathrm{FVC}_{\text {md }}=\mathrm{FVC}_{\text {max }}-\mathrm{FVC}_{\text {min }}
\end{gathered}
$$

where $w$ is the weight per land cover type. The weights were determined from the regression analysis between the FVC and the training FPAR data, and set to a constant value of 0.1 in cropland and 1.0 in forest. The minimum and maximum $\mathrm{FVC}\left(\mathrm{FVC}_{\min }\right.$ and $\mathrm{FVC}_{\max }$ ) were set to 0.02 and 0.93 , respectively.

Based on Eq. (1a), we estimated the FPAR as follows:

$$
\begin{gathered}
\mathrm{FVC}_{\text {cropland }}=0.003+0.73 \cdot \mathrm{FVC} \text { and } \\
\mathrm{FVC}_{\text {forest }}=0.1+0.68 \cdot \mathrm{FVC}
\end{gathered}
$$

using the FVC-FPAR relationship and compared the results with the FPAR validation data from MODIS; the validation data were selected at random from the reference data. The results of a correlation analysis
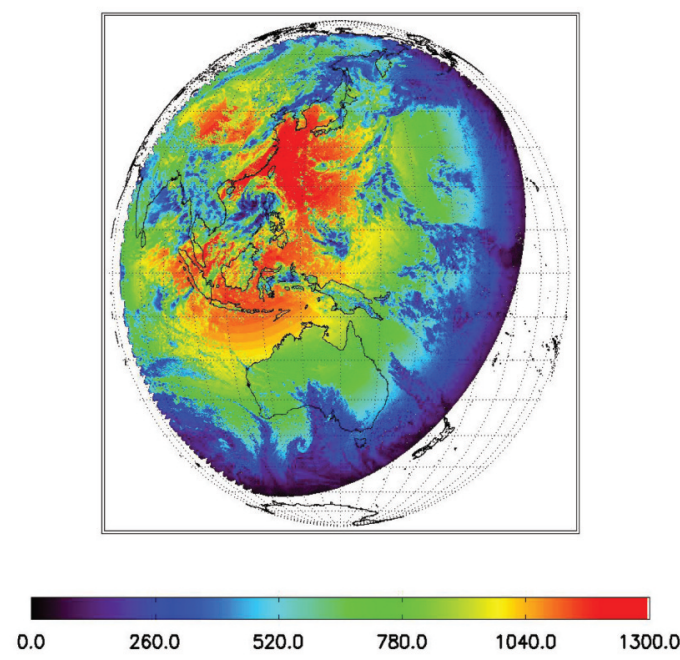

Fig. 4. Surface solar insolation from MTSAT-1R on 0433 UTC, August 1, 2006.

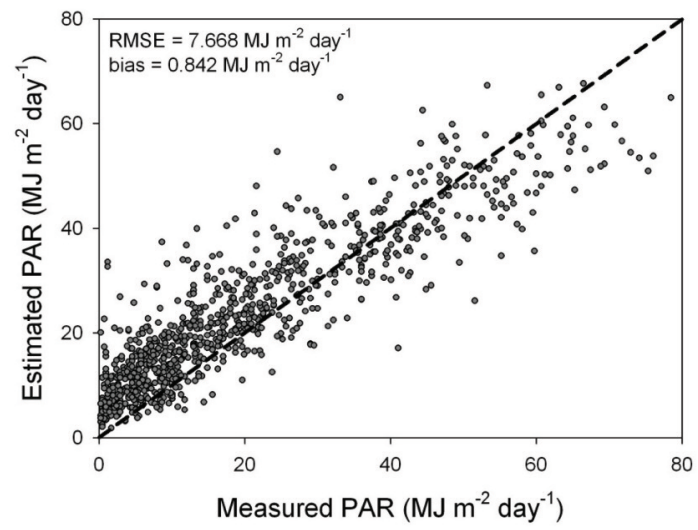

Fig. 5. Scatter plot of measured PAR and PAR estimated using new cloud lookup table. 
between the validation FPAR data and the estimated FPAR, indicate that the correlation was good $\left(\mathrm{R}^{2}=\right.$ 0.8390). The Root Mean Square Error (RMSE) was 0.0739 and the bias was low $(-0.000438)$.

We estimated the incident PAR using the Solar Surface Insolation (SSI), which was obtained using the method of Yeom (2010). Fig. 4 shows the output SSI product for an MTSAT-1R scene captured on August 1,2006 at 0433 UTC. The trends shown in this image were a function of the solar position, specifically, the cosine of the solar zenith angle. The satellite-based insolation to $11 \times 11$ for comparison with ground-station measurements was spatially averaged (Yeom, 2010). Yeom presented a cloud factor optimized for the modified Kawamura physical model to calculate the attenuated cloud transmittance from MTSAT-1R channel data. When simulating cloudy attenuation with the cloud factor, this model does not use the brightness temperature from a lookup table. Values from a newly developed cloud lookup table, which are a function of solar zenith angle, were used to reflect those characteristics instead of relying on the corresponding brightness temperature. The new cloud lookup table for the presented SSI retrieval model was described in detail by Yeom (2010). Fig. 5 contains a scatter plot showing the relationship between the remotely sensed PAR and the pyranometer data using the new cloud lookup table. The RMSE was $7.668 \mathrm{MJ} \cdot \mathrm{m}^{-2} \cdot$ day $^{-1}$ and the bias was $0.842 \mathrm{MJ} \cdot \mathrm{m}^{-2} \cdot$ day $^{-1}$. The latter indicates significantly increased accuracy, and the results were better than in previous studies.

\section{3) Estimation of $\varepsilon_{g}$ using the modified VPM model}

We estimated FPAR on the basis of the VPM, which is a LUE-based, remote-sensing-oriented model developed by Xiao et al. (2004a, 2004b). The VPM is based on the concept of partitioning vegetation canopies into Photosynthetically Active Vegetation (PAV) such as chloroplasts, and Non-Photosynthetically active Vegetation (NPV) such as the stem, branches, and cell walls. The VPM model may be described briefly by

$$
\begin{gathered}
\mathrm{GPP}=\varepsilon_{\mathrm{g}} \cdot \mathrm{FPAR}_{\mathrm{PAV}} \cdot \mathrm{PAR} \\
\varepsilon_{\mathrm{g}}=\varepsilon_{0} \cdot \mathrm{T}_{\text {scalar }} \cdot \mathrm{W}_{\text {scalar }} \cdot \mathrm{P}_{\text {scalar, }},
\end{gathered}
$$

where FPAR PAV $_{\text {is }}$ the fraction of PAR absorbed by PAV and $\varepsilon_{\mathrm{g}}$ is the LUE under environmental stress. Parameter $\varepsilon_{0}$ is the apparent quantum yield or maximum LUE, and $T_{\text {scalar }}, W_{\text {scalar }}$, and $P_{\text {scalar }}$ are the environmental stress indices of temperature, water, and leaf phenology on LUE, respectively. In the current version of the VPM model, FPAR PAV $_{\text {is }}$ assumed to be a linear function of the enhanced vegetation index (EVI) (Xiao et al., 2004a, b). However, we estimated FPAR using a corrected NDVI instead of the EVI. At each time step, $T_{\text {scalar }}$ is estimated using the equation developed for the Terrestrial Ecosystem Model (Raich et al., 1991),

$$
\mathrm{T}_{\text {scalar }}=\frac{\left(\mathrm{T}-\mathrm{T}_{\min }\right)\left(\mathrm{T}-\mathrm{T}_{\max }\right)}{\left(\left[\left(\mathrm{T}-\mathrm{T}_{\min }\right)\left(\mathrm{T}-\mathrm{T}_{\max }\right)\right]-\left(\mathrm{T}-\mathrm{T}_{\mathrm{opt}}\right)^{2}\right.}
$$

where $T_{m i n}, T_{m a x}$, and $T_{\text {opt }}$ are the minimum, maximum, and optimal temperature for photosynthetic activities, respectively. If air temperature falls below $T_{\min }$, then $T_{\text {scalar }}$ is set to zero. The effect of water on plant photosynthesis, $W_{\text {scalar }}$, has been estimated as a function of soil moisture and/or VPD in a number of production efficiency models (Field et al., 1995; Prince and Goward, 1995; Running et al., 2000). As a first-order approximation, we propose a simple alternative approach that uses a satellite-derived water index to estimate the seasonal dynamics of $W_{\text {scalar }}$ (Xiao et al., 2004a, 2004b),

$$
\mathrm{W}_{\text {scalar }}=\frac{1+\mathrm{LSWI}}{1+\mathrm{LSWI}_{\max }}
$$

where $L S W I_{\max }$ is the maximum Land Surface Water Index (LSWI) during the plant-growing season for individual pixels. We used a parallel water index, which is similar in mathematical formulation to the NDWI, that uses reflectance values in the 0.86 and $1.24 \mu \mathrm{m}$ 
spectral bands of hyperspectral data (Gao, 1996). Parameter $P_{\text {scalar }}$ is included in Eq. (4) to account for the effect of leaf phenology (leaf age) on photosynthesis at the canopy level. In this version of the VPM model, the calculation of $P_{\text {scalar }}$ is dependent on the leaf longevity. For a canopy that is dominated by leaves with a life expectancy of one year, $P_{\text {scalar }}$ is calculated at two different phases as a linear function (Xiao et al., 2004b) using

$$
\mathrm{P}_{\text {scalar }}=\frac{1+\text { LSWIa }}{2}
$$

Likewise, in this study, calculation of $P_{\text {scalar }}$ used the NDWI instead of the LSWI.

We ran the VPM model (Xiao et al., 2004a, 2004b) to estimate $\varepsilon_{\mathrm{g}}$, using LST, meteorological data (air temperature, $T_{a}$ ), and NDWI. First, LST provided in the MODIS product was used to measure the $T_{a}$ retrieval accuracy. The following was the equation of best fit:

$$
\mathrm{T}_{\mathrm{a}}=-2.3937+0.6235 \mathrm{LST}+0.0092(\mathrm{LST})^{2}
$$

We calculated Ta values using Eq. (8), plotted $T_{a}$ recorded by meteorological stations, and estimated $T_{a}$ from MODIS LST (Fig. 6). The RMSE was $2.6758^{\circ} \mathrm{C}$ and the bias was very low $\left(2.9 \times 10^{-9}{ }^{\circ} \mathrm{C}\right)$. Fig. 7 presents a comparison of estimated $T_{a}$ (black dots) and $T_{a}$ based on meteorological data (gray dots). We used NDWI time series data to assess the level of leaf and canopy water content of the seasonally moist tropical forest over the seasons (Fig. 8). The parameter set was used to calculate $T_{\text {scalar }}$ (see Eq. (5)). We used a minimum temperature $T_{\min }$ of $-12^{\circ} \mathrm{C}$, optimum temperature $T_{\text {opt }}$ of $24^{\circ} \mathrm{C}$, and maximum temperature Tmax of $31^{\circ} \mathrm{C}$, as implemented in the process-based Terrestrial Ecosystem Model. The next parameter set was calculated for $W_{\text {scalar }}$ and $P_{\text {scalar }}$ (see Eqs. (6 and 7)). Estimation of the maximum NDWI value during the plant-growing season was selected as an estimate of $N D W I_{\max }$.

We determined each scalar using the above equations. Fig. 9 illustrates the seasonal dynamics of

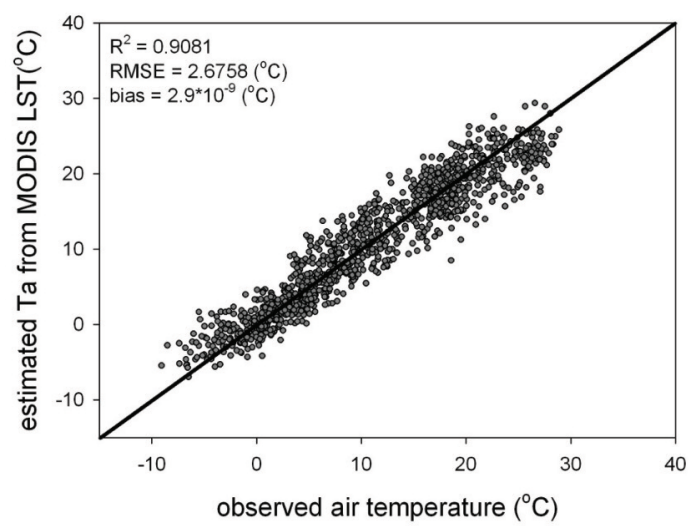

Fig. 6. Scatter plot of air temperature observed by meteorological stations and estimated $T_{a}$ from MODIS LST.

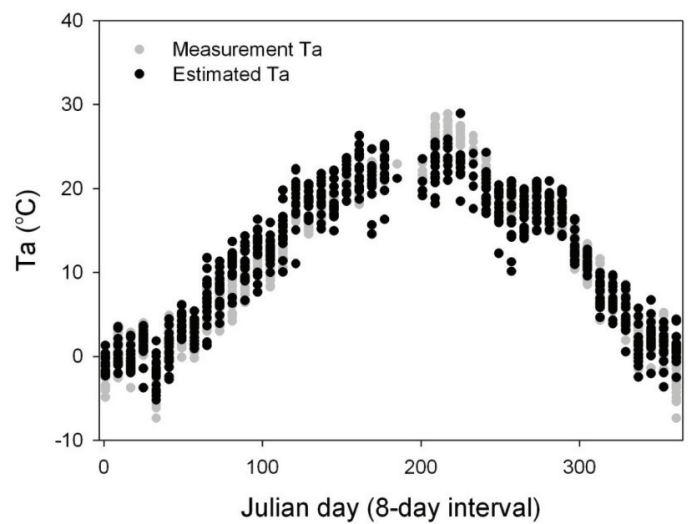

Fig. 7. Comparison of estimated $\mathrm{T}_{\mathrm{a}}$ and air temperature based on meteorological data.

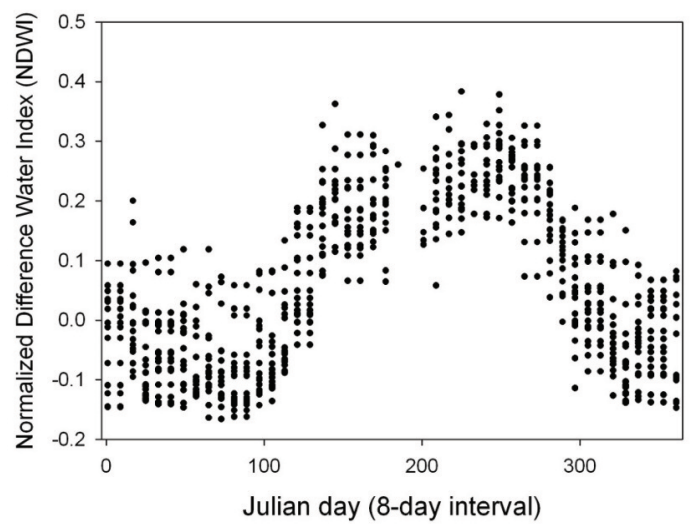

Fig. 8. Seasonal dynamics of NDWI from the study area.

the temperature scalar $T_{\text {scalar }}$, water scalar $W_{\text {scalar }}$, and leaf phenology scalar $P_{\text {scalar }}$ for the simulation of the VPM model. A field-based light addition/ augmentation experiment for rainforest trees in Panama has suggested that light, rather than water, temperature, 

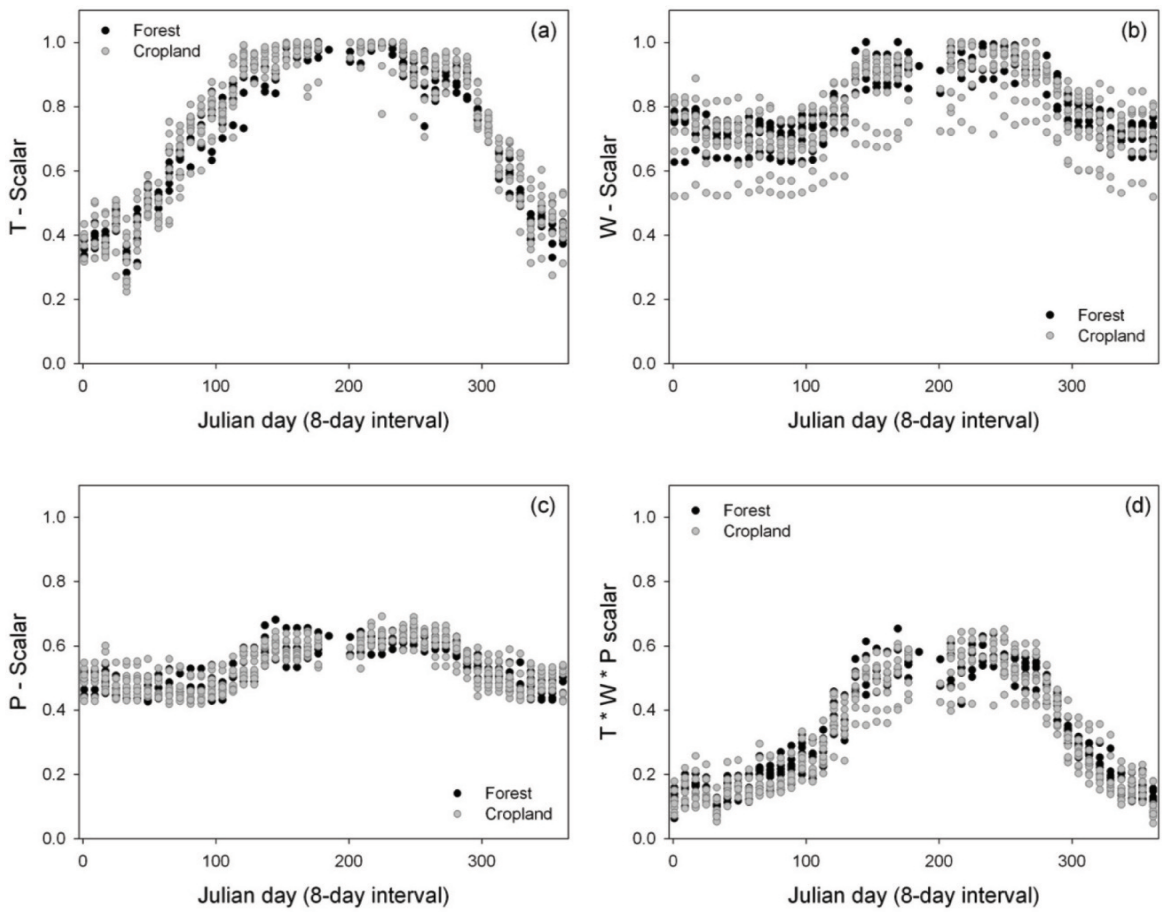

Fig. 9. Seasonal dynamics of (a) temperature scalar ( $\left.\mathrm{T}_{\text {scalar }}\right)$, (b) water scalar $\left(\mathrm{W}_{\text {scalar }}\right)$, and (c) leaf phenology scalar $\left(\mathrm{P}_{\text {scalar }}\right)$ for the VPM model simulation.

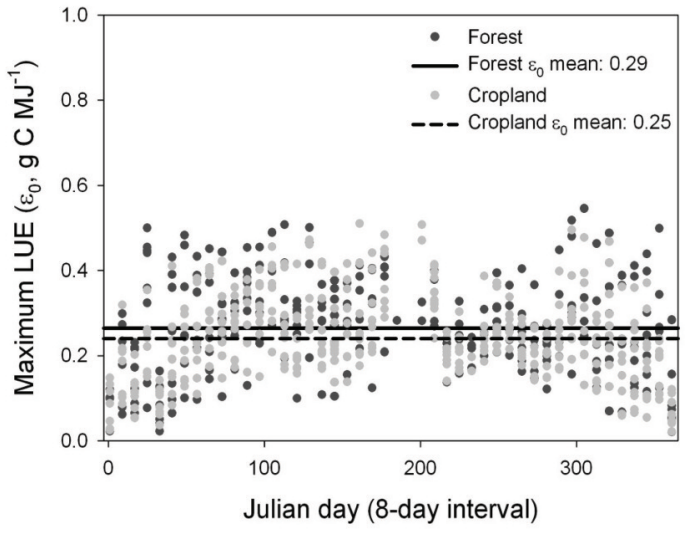

Fig. 10. Values of $\varepsilon_{0}$ derived from reference GPP: 0.25 for cropland and 0.29 for forest.

or leaf nitrogen, is the primary factor that limits $\mathrm{CO}_{2}$ uptake during the rainy season (Graham et al., 2003).

The maximum $\operatorname{LUE} \varepsilon_{0}$ is an important parameter for calculating GPP. We estimated $\varepsilon_{0}$ using the existing GPP equation:

$$
\varepsilon_{0}=\frac{\mathrm{GPP}}{\left(\mathrm{T}_{\text {scalar }} \cdot \mathrm{W}_{\text {scalar }} \cdot \mathrm{P}_{\text {scalar }}\right) \cdot \mathrm{FPAR} \cdot \mathrm{PAR}}
$$

The final product from this study was used as input
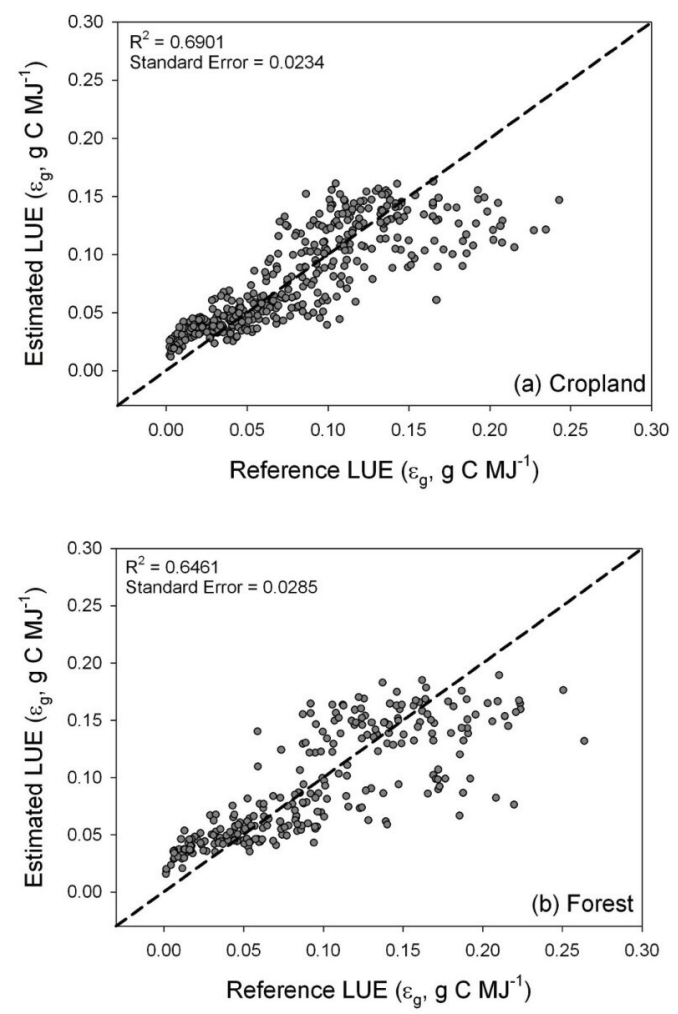

Fig. 11. Comparison between the validation and estimated $\varepsilon_{g}$ data. 
Table 3. Results ( $\mathrm{R}^{2}$, RMSE, bias) of comparison between validation $\varepsilon_{g}$ data and estimated $\varepsilon_{g}$

\begin{tabular}{c|c|c|c}
\hline \hline & Cropland & Forest & Total \\
\hline $\mathrm{R}^{2}$ & 0.6901 & 0.6461 & 0.6681 \\
\hline RMSE & 0.0319 & 0.0403 & 0.0355 \\
\hline Bias & -0.0015 & -0.0035 & -0.0023 \\
\hline \hline
\end{tabular}

data. In Eq. (9), GPP reference data was used to input data. Fig. 10 shows how the values of $\varepsilon_{0}$ derived from the reference GPP were set to 0.25 for cropland and 0.29 for forest.

We calculated $\varepsilon_{\mathrm{g}}$ using these variables. The comparison of the validation $\varepsilon_{\mathrm{g}}$ and estimated $\varepsilon_{\mathrm{g}}$ in Fig. 11 shows that a correlation existed $\left(R^{2}=0.69\right.$ for cropland and $\mathrm{R}^{2}=0.65$ for forest). Table 3 presents detailed information on the estimated $\varepsilon g$ accuracies. The RMSE was $0.0355 \mathrm{~g} \cdot \mathrm{C} \cdot \mathrm{MJ}^{-1}$ and the bias was -0.0023 . Low values were slightly overestimated, but this is not a bad result according to the overall RMSE and bias. With further validation and development, the VPM model has the potential for use on large spatial scales to estimate forest GPP. This would improve our understanding of the carbon cycle of the terrestrial biosphere (Xiao, 2004b).

\section{4) Accuracy assessment of estimated GPP}

We assessed the accuracy of the simulated GPP data by performing a linear regression with validation GPP data (Fig. 12). The RMSE and bias between the validation and estimated GPP data for different land cover types indicated that the GPP was simulated with reasonable accuracy (Table 4$)$. The linear regression model also produced good agreement among different land cover types. For all sites, the correlation was close and highly significant $\left(\mathrm{R}^{2}=0.8164, \mathrm{RMSE}=0.6126 \mathrm{~g}\right.$ $\cdot \mathrm{C} \cdot \mathrm{m}^{-2} \cdot \mathrm{d}^{-1}$, bias $\left.=-0.0271 \mathrm{~g} \cdot \mathrm{C} \cdot \mathrm{m}^{-2} \cdot \mathrm{d}^{-1}\right)$. Cropland had the highest correlation of the different ground types with high significance $\left(\mathrm{R}^{2}=0.83, \mathrm{RMSE}\right.$ $=0.56 \mathrm{~g} \cdot \mathrm{C} \cdot \mathrm{m}^{-2} \cdot \mathrm{d}^{-1}$, bias $\left.=-0.015 \mathrm{~g} \cdot \mathrm{C} \cdot \mathrm{m}^{-2} \cdot \mathrm{d}^{-1}\right)$ and forest had the lowest correlation with moderate significance $\left(\mathrm{R}^{2}=0.80, \mathrm{RMSE}=0.69 \mathrm{~g} \cdot \mathrm{C} \cdot \mathrm{m}^{-2} \cdot \mathrm{d}\right.$
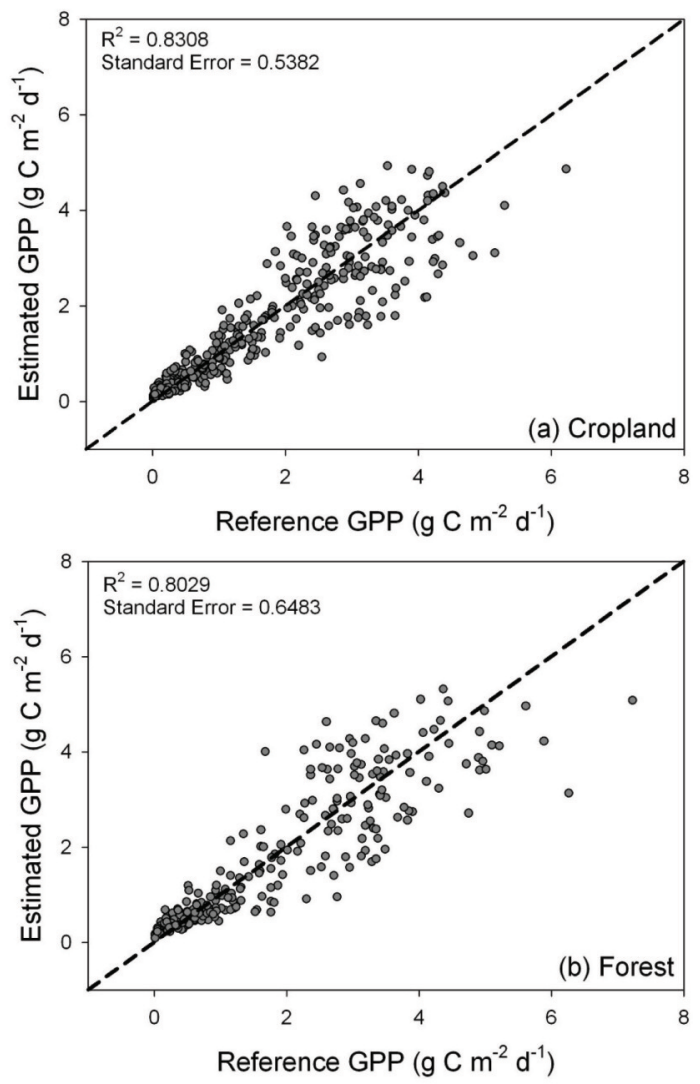

Fig. 12. Comparison between the validation and estimated GPP.

Table 4. Results ( $\mathrm{R}^{2}$, RMSE, bias) of comparison between validation GPP data and estimated GPP

\begin{tabular}{c|c|c|c}
\hline \hline & Cropland & Forest & Total \\
\hline $\mathrm{R}^{2}$ & 0.8308 & 0.8029 & 0.8164 \\
\hline RMSE & 0.5591 & 0.6856 & 0.6126 \\
\hline Bias & -0.0149 & -0.0455 & -0.0271 \\
\hline \hline
\end{tabular}

Table 5. Comparison with error statistics of GPP calculated using various models for the study period

\begin{tabular}{c|c|c|c|}
\hline \hline Method & $\mathrm{R}^{2}$ & $\begin{array}{c}\mathrm{RMSE} \\
\left(\mathrm{g} \cdot \mathrm{C} \cdot \mathrm{m}^{-2} \cdot \mathrm{d}^{-1}\right)\end{array}$ & $\begin{array}{c}\text { Bias } \\
\left(\mathrm{g} \cdot \mathrm{C} \cdot \mathrm{m}^{-2} \cdot \mathrm{d}^{-1}\right)\end{array}$ \\
\hline $\begin{array}{c}\text { GPP by TURC } \varepsilon_{g} \\
\text { model }\end{array}$ & 0.6461 & 2.3263 & 2.1289 \\
\hline $\begin{array}{c}\text { GPP by Ruimy's } \\
\text { FPAR model }\end{array}$ & 0.8899 & 0.7689 & -0.5652 \\
\hline Present study & 0.8164 & 0.6126 & -0.0271 \\
\hline \hline
\end{tabular}

${ }^{1}$, bias $\left.=-0.046 \mathrm{~g} \cdot \mathrm{C} \cdot \mathrm{m}^{-2} \cdot \mathrm{d}^{-1}\right)$.

We also compared with GPP calculated to be using input variable presenting in other model (Fig. 13). Fig. 13 shows a comparison between validation GPP data 

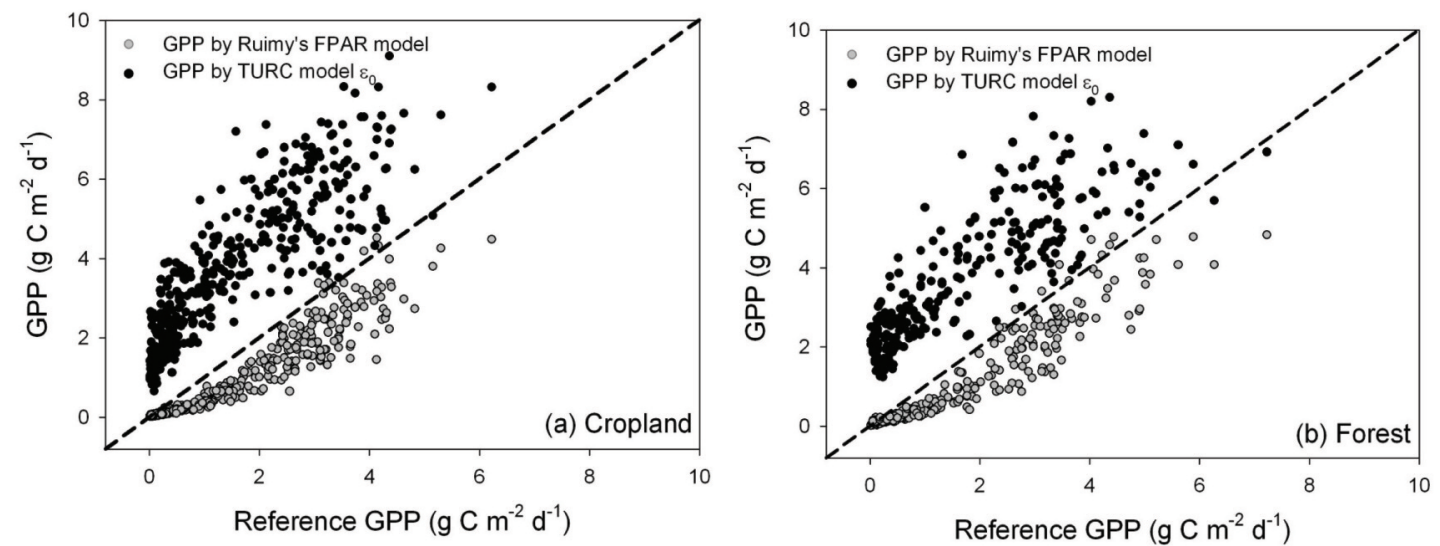

Fig. 13. Comparison between validation GPP data and GPP data from other models (Ruimy's FPAR model and TURC $\varepsilon_{0}$ model).

Reference GPP vs. Estimated GPP
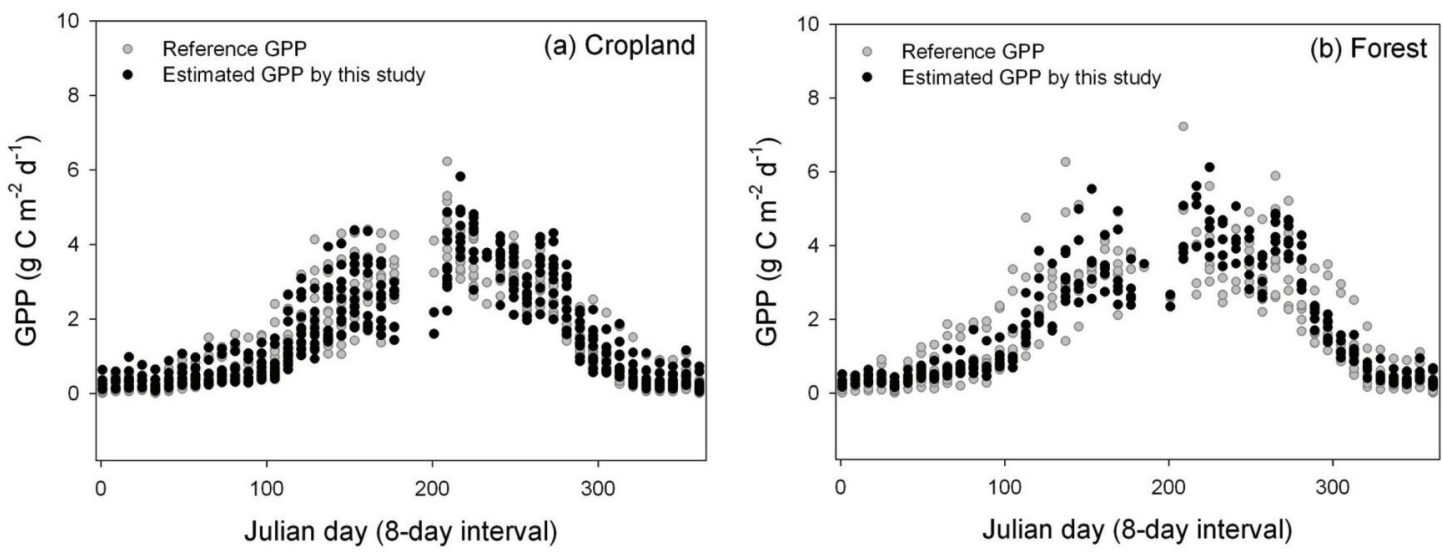

Fig. 14. Comparison of seasonal dynamics between reference and estimated GPP data.

Reference GPP vs. GPP by TURC model
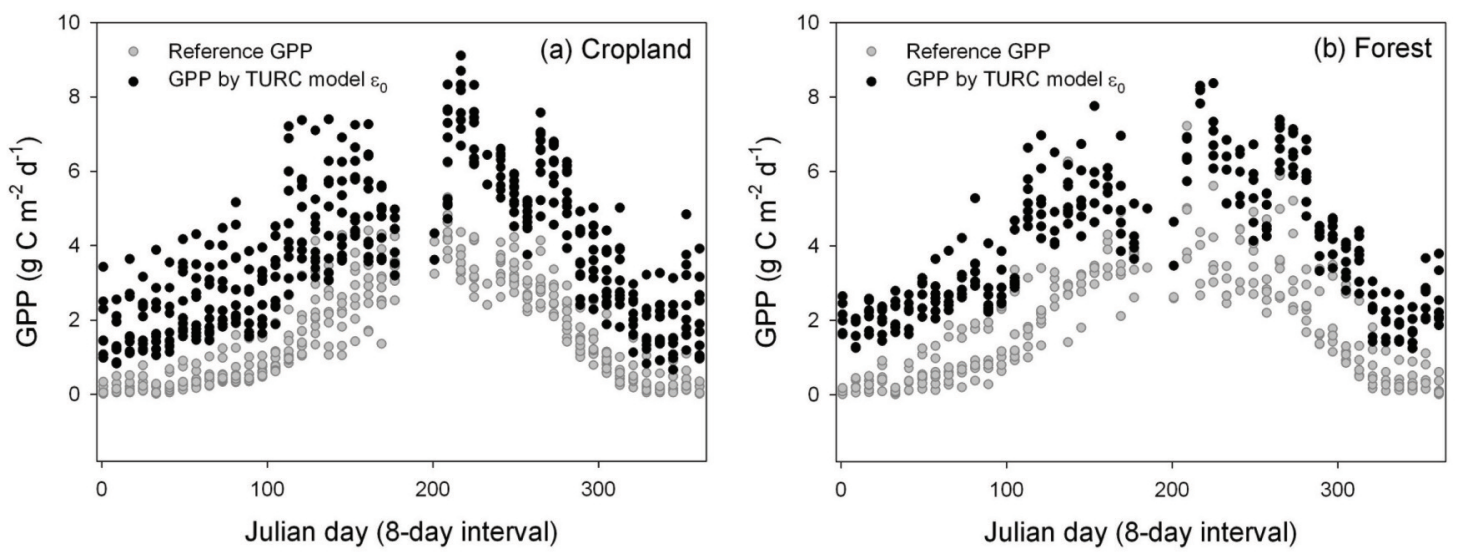

Fig. 15. Comparison of seasonal dynamics between reference GPP data and GPP data from the TURC $\varepsilon_{0}$ model.

and other models (Ruimy's FPAR model and the TURC $\varepsilon_{0}$ model) and Table 5 provides detailed information about the estimated GPP accuracies. As shown in Table 5 and Figs. 14-16, our method resulted 
Reference GPP vs. GPP by Ruimy's model
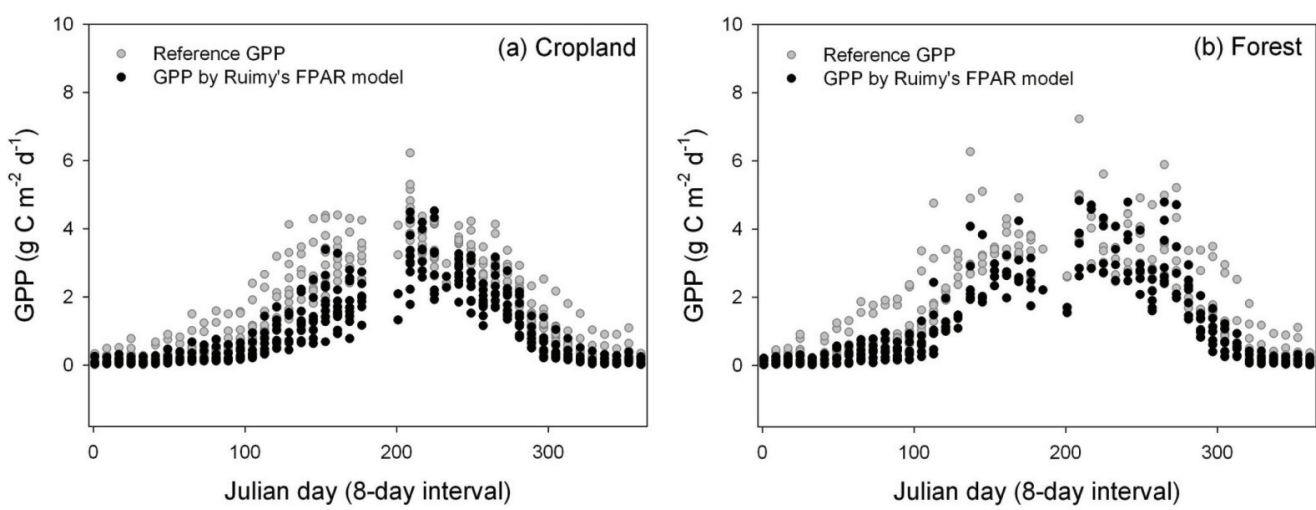

Fig. 16. Comparison of seasonal dynamics between reference GPP data and GPP data from Ruimy's FPAR model.
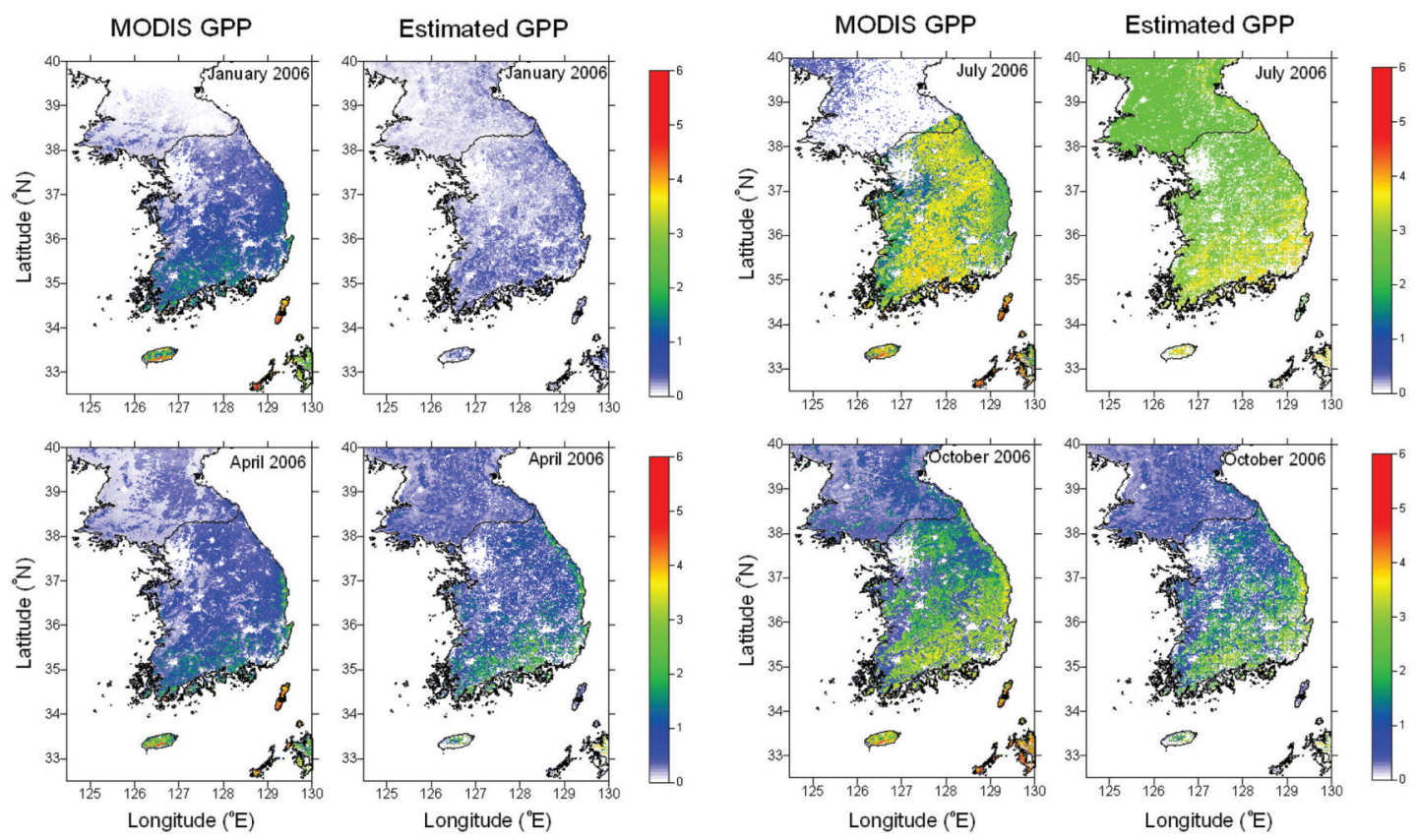

Fig. 17. Comparison of spatial patterns between MODIS GPP and estimated GPP (January, April, July, and October, 2006).

in overestimation or underestimation compared to other studies over the Korean peninsula. Even so, the final estimated GPP was better than that in other studies, as supported by statistical results (Table 5). The estimated GPP was closer for cropland than for forest (Fig. 14).

Fig. 17 compares spatial GPP patterns with MODIS and estimated GPP values for January, April, July, and October. A large portion of the July MODIS GPP data is missing. This illustrates clearly that even though MODIS global products are readily available, they contain errors, and input variables may not be corrected properly. In this study, errors in the estimated GPP were observed in MODIS products. Therefore, it is unreasonable to use them in research without improved processing.

\section{Conclusions}

We tested the performance of the MODIS 
operational algorithm on satellite data when calculating GPP. Typically, using GPP global product results in a regional mismatch over Korea and using MODIS GPP data and tends to produce poor GPP estimates. To solve this problem, we estimated each of the GPP component variables separately to improve the GPP estimates. We compared our GPP estimates with validation GPP data to assess their accuracy. For all sites, the correlation was close with high significance $\left(R^{2}=0.8164\right.$, RMSE $=0.6126 \mathrm{~g} \cdot \mathrm{C} \cdot \mathrm{m}^{-2} \cdot \mathrm{d}^{-1}$, bias $\left.=-0.0271 \mathrm{~g} \cdot \mathrm{C} \cdot \mathrm{m}^{-2} \cdot \mathrm{d}^{-1}\right)$. We also compared our results to those of other models. The component variables tended to be either over- or under-estimated when compared to those in other studies over the Korean peninsula, although the estimated GPP was better.

This work underscores the importance of studying extreme environments where large interannual variations in photosynthetic activity and hydrologic regime occur. This importance extends to model and algorithm intercomparison studies. The results of this study will likely improve carbon cycle modeling by capturing finer patterns with an integrated method of remote sensing. We hope this method will improve regional GPP modeling to some extent by introducing pixel-level resolution.

\section{Acknowledgement}

This research was a part of the project titled "Satellite based carbon monitoring system" funded by the Ministry of Oceans, Fisheries Affairs, Korea.

\section{Reference}

Barford, C.C., S.C. Wofsy, M.L. Goulden, J.W. Munger, E.H. Pyle, S.P. Urbanski, L. Hutyra, S.R. Saleska, D. Fitzjarrald and K. Moore, 2001. Factors controlling long- and short-term sequestration of atmospheric $\mathrm{CO}_{2}$ in a midlatitude forest. Science, 294: 1688-1691.

Coops, N.C., C.J. Ferster, R.H. Waring and J. Nightingale, 2009. Comparison of three models for predicting gross primary production across and within forested ecoregions in the contiguous United States. Remote Sensing of Environment, 113: 680-690.

Cohen, W.B., T.K. Maiersperger, S.T. Gower, D.P. Turner and S.W. Running, 2003. Comparisons of land cover and LAI estimates derived from ETM+ and MODIS for four sites in North America: a quality assessment of provisional MODIS products. Remote Sensing of Environment, $88,233-255$.

Field, C.B., 1991. Ecological scaling of carbon gain to stress and resource availability. In Response of Plants to Multiple Stresses. Physiological Ecology: a series of Monographs, Texts, and Treatises, Academic Press, San Diego, 35-65.

Field, C.B., J.T. Randerson and C.M. Malmstrom, 1995. Global net primary productioncombining ecology and remote-sensing. Remote Sensing of Environment, 51: 74-88.

Gao, B.C., 1996. NDWI-A normalized difference water index for remote sensing of vegetation liquid water from space. Remote Sensing of Environment, 58: 257-266.

Gebremichael, M. and A.P. Barros, 2006. Evaluation of MODIS Gross Primary Productivity (GPP) in tropical monsoon regions. Remote Sensing of Environment, 100: 150-166.

Goetz, S.J. and S.D. Prince, 1999. Modeling terrestrial carbon exchange and storage: evidence and implications of functional convergence in lightuse efficiency. Advances in Ecological Research, 28: 57-92.

Graham, E.A., S.S. Mulkey, K. Kitahima, N.G.Phillips and S.J. Wright, 2003. Cloud cover limits net $\mathrm{CO}_{2}$ uptake and growth of a rainforest tree 
during tropical rainy seasons. Proceeding of the National Academy of Sciences of the United States of America, 100: 572-576.

Heinsch, F.A., M. Reeves, P. Votava, S. Kang, C. Mailesi, M. Zhao, J. Glassy, W.M. Jolly, R. Loehman, C.F. Bowker, J.S. Kimball, R.R. Nemani, S.W. Running, 2003, User's guide GPP and NPP (MOD17A2/A3) products NASA MODIS land algorithm. Available online at: http://www.forestry.umt.edu/ntsg/.

IPCC (Intergovernmental Panel on Climate Change)., 2001. Climate change 2001: The scientific basis. In Houghton, J. T., Y. Ding, D. J. Griggs, M. Noguer, P. J. van der Linden, and D. Xiaosu (Eds.), Contribution of working group 1 to the third assessment report of the IPCC, 7 (UK: Cambridge University Press).

Jung, M., M. Verstraete, N. Gobron, M. Reichstein, D. Papale, A. Bondeau, R. Monica, P. Bernard, 2008. Diagnostic assessment of European gross primary production. Global Change Biology, 14: 2349-2364.

Knutson, T.R., T.L. Delworth, K. Dixon and R.J. Stouffer, 1999. Model assessment of regional surface temperature trends (1947-1997). Journal of Geophysical Research, 104: 30981-30996.

Monteith, J.L., 1972. Solar radiation and productivity in tropical ecosystems. Journal of Applied Ecology, 9: 747-766.

Monteith, J.L., 1977. Climate and efficiency of crop production in Britain. Philosophical Transactions of the Royal Society of London, Series B, Biological Sciences, 284: 277-294.

Myneni, R., Y. Knyazikhin, J. Glassy, P. Votava and N. Shabanov, 2003. User's guide FPAR, LAI (ESDT: MOD15A2) 8-day composite NASA MODIS land algorithm. Available online at: http://www .cybele.bu.edu/modismisr/products/ modis/.

Nemani, R.R., C.D. Keeling, H. Hashimoto, W.M.
Jolly, S.C. Piper, C.J. Tucker, R.B. Myneni, S.W. Running, 2003. Climate-driven increases in global terrestrial net primary production from 1982 to 1999 . Science, 300: 1560-1563.

Nemani, R.R., W. White, P. Thornton, K. Nishida, S. Reddy, S. Jenkins, S. Running, 2002. Recent trends in hydrologic balance have enhanced the terrestrial carbon sink in the United States. Geophysical Research Letters, 29: 106.1-106.4.

Pi, K.J. and K.S. Han, 2010. Retrieval of the fraction of photosyntherically active radiation (FPAR) using SPOT/VEGETATION over Korea. Korean Journal of Remote Sensing, 26: 537-547.

Prince, S.D. and S.N. Goward, 1995. Global primary production: a remote sensing approach. Journal of Biogeography, 22: 815-835.

Raich, J.W., E.B. Rastetter, J.M. Melillo, D.W. Kicklighter, P.A. Steudler and B.J. Peterson, A. L. Grace, B. Moore III and C.J. Vorosmarty, 1991. Potential net primary productivity in South-America-application of a global-model. Ecological Applications, 1: 399-429.

Running, S.W., D.D. Baldocchi, D.P. Turner, S.T. Gower, P.S. Bakwin and K.A. Hibbard, 1999. A global terrestrial monitoring network integrating tower fluxes, flask sampling, ecosystem modeling and EOS satellite data. Remote Sensing of Environment, 70: 108-127. Running, S.W., P.E. Thornton, R. Nemani and J.M. Glassy, 2000. Global terrestrial gross and net primary productivity from the Earth Observing System. Methods in ecosystem science, 44-57 (New York: Springer Verlag).

Schimel, D., J. Melillo, H. Tian, A.D. McGuire, D. Kicklighter, T. Kittel, N. Rosenbloom, S. Running, P. Thornton, D. Ojima, W. Parton, R. Kelly, M. Sykes, R. Neilson, B. Rizzo, 2000. Contribution of increasing $\mathrm{CO}_{2}$ and climate to carbon storage by ecosystems in the united states. Science, 287: 2004-2006. 
Scott, P.A., S.F.B. Tett, G.S. Jones, M.R. Allen, J.F.B. Mitchell and G.J. Jenkins, 2000. External control of twentieth century temperature variations by natural and anthropogenic forcings. Science, 290: 2133-2137.

Turner, D.P., W.D. Ritts, W.B. Cohen, S.T. Gower, M. Zhao, S.W. Running, S.C. Wofsy, S. Urbanski, A.L. Dunn, and J.W. Munger, 2003. Scaling gross primary production (GPP) over boreal and deciduous forest landscapes in support of MODIS GPP product validation. Remote Sensing of Environment, 88: 256-270.

Wang, H., G. Jia, C. Fu, J. Feng, T. Zhao, and Z. Ma, 2010. Deriving maximal light use efficiency from coordinated flux measurements and satellite data for regional gross primary production modeling. Remote Sensing of Environment, 114: 2248-2258.

Wofsy, S.C., M.L. Goulden, J.W. Munger, S.M. Fan, P.S. Bakwin, B.C. Daube, S.L Bassow, F.A Bazzaz, 1993. Net exchange of $\mathrm{CO}_{2}$ in a mid- latitude-forest. Science, 260: 1314-1317.

Xiao, X., D. Hollinger, J.D. Aber, M. Goltz, E.A. Davidson and Q.Y. Zhang, 2004a. Satellitebased modeling of gross primary production in an evergreen needleleaf forest. Remote Sensing of Environment, 89: 519-534.

Xiao, X., Q. Zhang, B. Braswell, S. Urbanski, S. Boles, S. Wofsy, B. Moore III, D. Ojima, 2004 b. Modeling gross primary production of temperate deciduous broadleaf forest using satellite images and climate data. Remote Sensing of Environment, 91: 256-270.

Yeom, J.M. and K.S. Han, 2010. Improved estimation of surface solar insolation using a neural network and MTSAT-1R data. Computers \& Geosciences, 36:590-597.

Zhao, M., S.W. Running and R.R. Nemani, 2006. Sensitivity of MODIS terrestrial primary production to the accuracy of meteorological reanalyses. Journal of Geophysical Research Biogeosciences, 111: 1002-1014. 